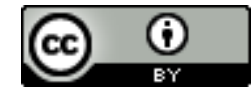

Esta obra está sob o direito de Licença Creative Commons Atribuição 4.0 Internacional.

\title{
RAIO X DA SAÚDE DO TRABALHADOR DA REDE SUS HOSPITALAR: DESAFIOS E PERSPECTIVAS
}

\author{
Suzana Peixoto de Araújo ${ }^{1}$ \\ Júlia Cláudia Tenório ${ }^{2}$ \\ Marcelo Henrique Santos ${ }^{3}$ \\ Betijane Soares de Barros ${ }^{4}$
}

\section{RESUMO}

A saúde dos trabalhadores está diretamente relacionada com as condições que os ambientes de trabalho proporcionam. Diante desse contexto societário, estão as condições de trabalho postas que impactam diretamente a saúde dos trabalhadores. O objetivo do trabalho foi realizar uma revisão de literatura sobre as condições de saúde dos trabalhadores da rede sus hospitalar, quais as possíveis causas de adoecimento desses profissionais, correlacionando com o ambiente de trabalho que estão inseridos. Na metodologia: Foram utilizadas base de dados eletrônicos como Scielo, ministério da saúde, livros. Para tanto, será analisado as condições de trabalho, e dando seguimento circunstanciadamente as condições dos trabalhadores da saúde. Os resultados foram analisadas as condições que o trabalhador se depara no âmbito do trabalho, e a contradição no que preconiza a Política Nacional de Segurança e Saúde no trabalho, a Política Nacional de Saúde do Trabalhador e da Trabalhadora, e o que contempla nas diretrizes no Sistema Único de Saúde.

Palavras-chave: Trabalho. Saúde do Trabalhador. Hospital.

Submetido em março de 2020 e aceito em maio de 2020.

\footnotetext{
1 Mestranda do Curso de Pós-Graduação em Saúde Pública, Absoulute Christian University. Email: suzanapeixoto123@hotmail.com.

2 Mestranda do Curso de Pós-Graduação em Saúde Pública, Absoulute Christian University. Email: julianatenorio2017@gmail.com.

3 Mestrando do Curso de Pós-Graduação em Saúde Pública, Absoulute Christian University. Email: drmarcelo_psf_odonto@yahoo.com.br.

${ }^{4}$ Doutora em Ciências da Educação (Faculdade de Ciências, Letras e Educação do Paraná). Doutora em Ciências da Saúde (Absoulute Christian University). Mestre em Ciências da Saúde (UFAL). Diretora do IMAS.
} 


\section{INTRODUÇÃO}

A saúde do trabalhador vem se tornando uma preocupação crescente em decorrência da grande incidência de desgaste na saúde (física e psíquica). O contexto societário em que se intensifica a força de trabalho, expressa, dentre outras situações, na instabilidade dos vínculos empregatícios, na intensidade da jornada de trabalho e das demandas profissionais e nos baixos salários. Situação que afeta os trabalhadores das diversas áreas, inclusive aqueles que atuam na área de saúde.

Dessa forma, o sistema capitalista incute diretamente no indivíduo a necessidade de produzir cada vez mais, e assim se integrar a sociedade. Para (PAI, 2008), o trabalho configura-se como sendo um dos fatores determinantes da situação de saúde dos trabalhadores, podendo contribuir para seu fortalecimento ou sua deterioração.

Os trabalhadores que atuam na Rede Sus Hospitalar como os demais trabalhadores, se deparam com os efeitos da reestruturação produtiva implementadas mundialmente desde a década de 1970 e efetivadas no Brasil a partir dos anos 1990, gerando consequências decorrentes da flexibilização e da precarização. Acompanhado das novas formas de trabalho, surgem o aumento da produção, a terceirização, a precarização e o trabalho informal, ocasionando na insegurança do trabalhador em manter-se alinhado ao que é posto no ambiente de trabalho (ANTUNES, 2013).

Na sociedade capitalista, o trabalho representa um veículo de exploração e desigualdade social e, por conseguinte, atua muitas vezes como desencadeador ou intensificador de desgaste da saúde (DIAS, 2011).

Os profissionais que atuam na área da saúde especificamente, vivenciam efeitos nocivos à saúde decorrentes das condições de trabalho. Os profissionais de hospitais públicos de urgência e emergência, de modo geral, lidam com precárias condições de trabalho, como insuficiência de profissionais, insumos, equipamentos, estruturas físicas inadequadas, falta de leitos hospitalares, superlotação e defasagem salarial (DUBEUX, FREESE, REIS, 2010).

Vale salientar que mesmo com os avanços a partir da implementação do sistema único de saúde (SUS), com a ampliação de acesso aos serviços de saúde e consequente melhoria no perfil epidemiológico, em contrapartida temos diversas fragilidades em sua operacionalização (PAIM, 2013).

Nessa perspectiva, de acordo com a Lei $\mathrm{n}^{\circ}$ 8.080/90 aborda a Saúde do Trabalhador e suas atribuições, inseridas no art. $6^{\circ}, \S 3^{\circ}$, baseiam-se no conceito de que 
a ST compreende um conjunto de ações de vigilância epidemiológica e sanitária, promoção, proteção, recuperação, reabilitação e que os trabalhadores se submetem a riscos e agravos oriundos das condições de trabalho. São oito incisos que dão conta desse espectro de abrangência.

Em se tratando das necessidades em saúde no âmbito do SUS, é considerado como um direito de cidadania, articulado

\section{METODOLOGIA}

Trata-se revisão de literatura, não sistemática, cujas fontes de pesquisas foram

\section{RESULTADOS E DISCUSSÕES}

\section{Fatores psicossociais no trabalho hospitalar}

As condições e organizações inadequadas no âmbito do trabalho hospitalar configuram fatores psicossociais no trabalho, desencadeadaspor respostas físicas e emocionais prejudiciais como o estresse entre outras doenças, afetando diretamente trabalhadores, paciente $\mathrm{e}$ instituição. As cargas físicas e mentais do trabalho hospitalar são intensas, tanto nas atividades de cuidado direto ao paciente como nas atividades administrativas e de apoio (HAMMIG, 2012). Em se tratando de saúde mental do trabalhador, a promoção da saúde mental tem especial relevância no ambiente de trabalho, uma vez que é juntamente com as políticas econômicas e sociais estabelecidos do processo saúdedoença. No contexto atual do SUS, a continuidade da luta pelo direito à saúde implica a defesa articulada das medidas que melhorem a qualidade de vida e que assegurem o acesso às ações e serviços de saúde que sejam necessários. (MATTOS, 2005, P. 43).

documentos de sites oficiais, artigos científicos e livros obtidos em bibliotecas virtuais e físicas.

considerada um fator importante no desenvolvimento de problemas físicos e mentais (BRUSELAS, 2016).

A relevância dos fatores psicossociais no trabalho para o setor hospitalar tem crescido nas últimas décadas, influenciada por mudanças demográficas e epidemiológicas, disseminação de tecnologias de alta complexidade e crescente exigência de segurança assistencial (HAMMIG, 2012). Nesta perspectiva, os trabalhadores lidam constantemente com a ausência e precarização de insumos necessários para exercerem as atividades, entre outros aspectos como o ambiente físico, equipamentos, não reconhecimento profissional, ritmos e jornadas excessivas. 
O trabalho desprovido de significação e sem suporte social, não reconhecido, torna-se fonte de ameaça à integridade física e psíquica do indivíduo.

No campo da saúde, a prevalência de morbidade psiquiátrica em profissionais de saúde do serviço de emergência hospitalar é de 36,8\% (MOMENI, 20162018). Em um ambiente de trabalho geralmente estressante, o que implica, entre outros, o manejo de incertezas diagnósticas e terapêuticas, que pode produzir Burnout (JOHNSTON, 2016-2018).

Entretanto, as consequências advindas das condições de trabalho, sofrem impactos que vão além do seu ambiente de trabalho, fazendo com que o trabalhador se exponha a doenças, ao desemprego, ao afastamento do trabalho e situações conflituosas. $\mathrm{O}$ afastamento do trabalho por motivos de doença implica múltiplas e diversas repercussões psicossociais ao indivíduo. Tanto pela participação no trabalho como pelo desemprego, parte do valor atribuído a si mesmo e pela sociedade deixa de existir, causando sentimentos de exclusão e o sofrimento intrínseco daí decorrente (SOUZA; FAIMAN, 2007).

$\mathrm{O}$ adoecimento retira do trabalhador o espaço conquistado no mercado o reconhecimento como cidadão, levando-o a sentir-se incapaz. Nos relatos das pesquisas realizadas por Ghisleni e Merlo (2005), os trabalhadores revelam que ao serem afastados do trabalho, sentiram-se abalados tanto financeiramente como emocionalmente, pois gostavam do que faziam e, apesar de serem explorados e expostos as péssimas condições que eram postas, consideravam o trabalho um mal necessário, já que precisavam da renda obtida por sua força de trabalho para manter as suas necessidades.

No entanto, a precarização do trabalho não faz com que o trabalhador abandone seu emprego, pois além de ter o emprego como meio de subsistência, existe um exército industrial de reserva que logo pode substitui-lo. Assim, o medo do desemprego é um dos fatores que levam o trabalhador à condição de explorado, sujeitando-o ao assédio moral e a outras consequências, de acordo com Hirigoye (2011, p. 65) o assédio moral é:

“toda e qualquer conduta abusiva
manifestando-se sobretudo por
comportamentos, palavras, atos,
gestos, escritos que possam trazer
dano à personalidade, à dignidade ou
à integridade física ou psíquica de uma
pessoa, pôr em perigo seu emprego ou
degradar o ambiente de trabalho."
assédio moral engloba a
desqualificação, o isolamento, a atribuição de tarefas de menor valor, a indução ao erro, o assédio sexual, a exclusão, as mudanças de horários e de atividades sem prévio aviso, abusos de poder etc. Para Hirigoyen, o psicoterror gera hostilidade e maldade, ocasionando o aniquilamento psíquico que pode levar ao suicídio. Muito mais que uma 
relação conflituosa, o assédio moral no trabalho está relacionado a abusos hierárquicos, à dominação e à intencionalidade (HIRIGOYEN, 2015).

Assim, observa-se que o trabalhador vítima de assédio moral tem sua vida integralmente comprometida, uma vez que os sintomas podem ser comportamentais, físicos e psicológicos. O indivíduo passa a se distanciar tanto de seu ambiente de trabalho quanto do familiar.

\section{Política nacional de saúde do(a) trabalhador(a)}

O Ministério do Estado da Saúde, no uso da atribuição que lhe confere o inciso II do parágrafo único art. 87 da Constituição, e Considerando que compete ao Sistema Único de Saúde (SUS) a execução das ações de saúde do trabalhador, conforme determina a Constituição Federal; o papel do Ministério da Saúde de coordenar nacionalmente a política de saúde do trabalhador, conforme o disposto no inciso V do art. 16 da Lei $\mathrm{n}^{\circ}$ 8.080, de 19 de setembro de 1990; Considerando o alinhamento entre a política de saúde do trabalhador e a Política Nacional de Segurança e Saúde no Trabalho (PNSST), instituída por meio do Decreto $\mathrm{n}^{\circ} 7.602$, de 7 de novembro de 2011:

Art. $1^{\circ}$ Fica instituída a Política Nacional de Saúde do Trabalhador e da Trabalhadora.
Art. $2^{\circ}$ A Política Nacional de Saúde do Trabalhador e da Trabalhadora tem como finalidade definir os princípios, as diretrizes e as estratégias a serem observados pelas três esferas de gestão do Sistema Único de Saúde (SUS), para o desenvolvimento da atenção integral à saúde do trabalhador, com ênfase na vigilância, visando a promoção e a proteção da saúde dos trabalhadores e a redução da morbimortalidade decorrente dos modelos de desenvolvimento e dos processos produtivos.

Art. $3^{\mathbf{o}}$ Todos os trabalhadores, homens e mulheres, independentemente de sua localização, urbana ou rural, de sua forma de inserção no mercado de trabalho, formal ou informal, de seu vínculo empregatício, público ou privado, assalariado, autônomo, avulso, temporário, cooperativados, aprendiz, estagiário, doméstico, aposentado ou desempregado são sujeitos desta Política.

Parágrafo único. A Política Nacional de Saúde do Trabalhador e da Trabalhadora alinha-se com o conjunto de políticas de saúde no âmbito do SUS, considerando a transversalidade das ações de saúde do trabalhador e o trabalho como um dos determinantes do processo saúdedoença.

Art. $4^{\circ}$ Além do disposto nesta Portaria, a Política Nacional de Saúde do Trabalhador e da Trabalhadora reger-se-á, 
de forma complementar, pelos elementos informativos constantes do Anexo I a esta Portaria.

Art. $6^{\circ}$ Para fins de implementação da Política Nacional de Saúde do Trabalhador e da Trabalhadora, dever-se-á considerar a articulação entre:

As ações individuais, de assistência e de recuperação dos agravos, com ações coletivas, de promoção, de prevenção, de vigilância dos ambientes, processos e atividades de trabalho, e de intervenção sobre os fatores determinantes da saúde dos trabalhadores;

As ações de planejamento e avaliação com as práticas de saúde; e o conhecimento técnico e os saberes, experiências e subjetividade dos trabalhadores e destes com as respectivas práticas institucionais.

Parágrafo único. A realização da articulação tratada neste artigo requer mudanças substanciais nos processos de trabalho em saúde, na organização da rede de atenção e na atuação multiprofissional e interdisciplinar, que contemplem a complexidade das relações trabalho-saúde.

Art. $7^{\circ}$ A Política Nacional de Saúde do Trabalhador e da Trabalhadora deverá contemplar todos os trabalhadores priorizando, entretanto, pessoas e grupos em situação de maior vulnerabilidade, como aqueles inseridos em atividades ou em relações informais e precárias de trabalho, em atividades de maior risco para a saúde, submetidos a formas nocivas de discriminação, ou ao trabalho infantil, na perspectiva de superar desigualdades sociais e de saúde e de buscar a equidade na atenção.

Parágrafo único. As pessoas e os grupos vulneráveis de que trata o "caput" devem ser identificados e definidos a partir da análise da situação de saúde local e regional e da discussão com a comunidade, trabalhadores e outros atores sociais de interesse à saúde dos trabalhadores, considerando-se suas especificidades e singularidades culturais e sociais.

\section{Dos objetivos}

Art. $8^{\circ}$ São objetivos da Política Nacional de Saúde do Trabalhador e da Trabalhadora:

Fortalecer a Vigilância em Saúde do Trabalhador (VISAT) e a integração com os demais componentes da Vigilância em Saúde, o que pressupõe:

- identificação das atividades produtivas da população trabalhadora e das situações de risco à saúde dos trabalhadores no território;

- identificação das necessidades, demandas e problemas de saúde dos trabalhadores no território;

- realização da análise da situação de saúde dos trabalhadores; 
- intervenção nos processos e ambientes de trabalho;

- produção de tecnologias e intervenção, de avaliação e de monitoramento das ações de VISAT;

- controle e avaliação da qualidade dos serviços e programas de saúde do trabalhador, nas instituições e empresas públicas e privadas;

- produção de protocolos, de normas técnicas e regulamentares; e

- participação dos trabalhadores e suas organizações;

Promover a saúde e ambientes e processos de trabalhos saudáveis, o que pressupõe:

- estabelecimento e adoção de parâmetros protetores da saúde dos trabalhadores nos ambientes e processos de trabalho;

- fortalecimento e articulação das ações de vigilância em saúde, identificando os fatores de risco ambiental, com intervenções tanto nos ambientes e processos de trabalho, como no entorno, tendo em vista a qualidade de vida dos trabalhadores e da população circunvizinha;

- representação do setor saúde/saúde do trabalhador nos fóruns e instâncias de formulação de políticas setoriais e intersetoriais e às relativas ao desenvolvimento econômico e social;

- inserção, acompanhamento e avaliação de indicadores de saúde dos trabalhadores e das populações circunvizinhas nos processos de licenciamento e nos estudos de impacto ambiental;

- inclusão de parâmetros de proteção à saúde dos trabalhadores e de manutenção de ambientes de trabalho saudáveis nos processos de concessão de incentivos ao desenvolvimento, nos mecanismos de fomento e outros incentivos específicos;

- contribuição na identificação e erradicação de situações análogas ao trabalho escravo;

- contribuição na identificação e erradicação de trabalho infantil e na proteção do trabalho do adolescente; e

- desenvolvimento de estratégias e ações de comunicação de risco e de educação ambiental e em saúde do trabalhador;

Garantir a integralidade na atenção à saúde do trabalhador, que pressupõe a inserção de ações de saúde do trabalhador em todas as instâncias e pontos da Rede de Atenção à Saúde do SUS, mediante 
articulação e construção conjunta de protocolos, linhas de cuidado e matriciamento da saúde do trabalhador na assistência e nas estratégias e dispositivos de organização e fluxos da rede.

\section{Política nacional de segurança e saúde do trabalhador}

\section{Considerando os preceitos}

constitucionais do direito à saúde, à

previdência social e ao trabalho e a

necessidade de se estruturar a articulação

intragovernamental em relação às questões

de segurança e saúde do trabalhador, foi

constituído o Grupo de Trabalho

Interministerial MPS/MS/TEM, pela

Portaria Interministerial No. 153, de 13 de

fevereiro de 2004, com a atribuição de:

\begin{abstract}
"reavaliar o papel, a composição e a duração do Grupo Executivo Interministerial em Saúde do Trabalhador - GEISAT (instituído pela Portaria Interministerial MT/MS/MPAS n ${ }^{\circ}$ 7, de 25 de julho de 1997); b) analisar medidas e propor ações integradas e sinérgicas que contribuam para aprimorar as ações voltadas para a segurança e saúde do trabalhador; c)elaborar proposta de Política Nacional de Segurança e Saúde do Trabalhador, observando as interfaces existentes e ações comuns entre os diversos setores do Governo; d) analisar e propor ações de caráter intersetorial referentes ao exercício da garantia do direito à segurança e à saúde do trabalhador, assim como ações específicas da área que necessitem de implementação imediata pelos respectivos Ministérios, individual ou conjuntamente e e)compartilhar os sistemas de informações referentes à segurança e saúde dos trabalhadores existentes em cada Ministério.”
\end{abstract}

Ainda de acordo com a Lei Orgânica da Saúde (Lei Federal 8080/90) regulamenta os dispositivos constitucionais sobre a Saúde do Trabalhador. O artigo $6^{\circ}$, parágrafo $3^{\circ}$ estabelece:

"entende-se por saúde do trabalhador, para fins desta lei, um conjunto de atividades que se destina, através das ações de vigilância epidemiológica e vigilância sanitária, à promoção e proteção da saúde dos trabalhadores, assim como visa à recuperação e reabilitação da saúde dos trabalhadores submetidos aos riscos e agravos advindos das condições de trabalho, abrangendo: I - assistência ao trabalhador vítima de acidentes de trabalho ou portador de doença profissional e do trabalho; II participação, no âmbito de competência do Sistema Único de Saúde (SUS), em estudos, pesquisas, avaliação e controle dos riscos e agravos potenciais à saúde existentes no processo de trabalho; III participação, no âmbito de competência do Sistema Único de Saúde (SUS), da normatização, fiscalização e controle das condições de produção, extração, armazenamento, transporte, distribuição e manuseio de substâncias, de produtos, de PNSST versão de 12/11/2004 10 máquinas e de equipamentos que apresentam riscos à saúde do trabalhador; IV avaliação do impacto que as tecnologias provocam à saúde; V informação ao trabalhador e à sua respectiva entidade sindical e às empresas sobre os riscos de acidentes de trabalho, doença profissional e do trabalho, bem como os resultados de fiscalizações, avaliações ambientais e exames de saúde, de admissão, periódicos e de demissão, respeitados os preceitos da ética profissional; VI participação na normatização, fiscalização e controle dos serviços de saúde do trabalhador nas instituições e empresas públicas e privadas; VII revisão periódica da listagem oficial de doenças originadas no processo de trabalho, tendo na sua elaboração a colaboração das entidades sindicais; e VIII - a garantia ao sindicato dos 
trabalhadores de requerer ao órgão competente a interdição de máquina, de setor de serviço ou de todo ambiente de trabalho, quando houver exposição a risco iminente para a vida ou saúde dos trabalhadores."

38. O direito dos trabalhadores à redução dos riscos para a saúde presentes no trabalho, por meio de normas de saúde, higiene e segurança está inscrito no artigo 7o. da CF.

\section{A CF define a prerrogativa} exclusiva da União para legislar sobre o Direito do Trabalho e a obrigação de organizar, manter e executar a inspeção do trabalho.

Estão incluídas no campo de atuação do Sistema Único de Saúde - SUS (art 200), nos distintos níveis: a) - a execução de ações de saúde do trabalhador; b) a colaboração na proteção do meio ambiente, nele compreendido o do trabalho.

A competência privativa da União para legislar sobre Direito do Trabalho não

\section{CONCLUSÃO}

Considerando a necessidade de uma atenção à saúde do trabalhador, e de ser instituída uma política de saúde e a Política Nacional de Segurança e Saúde no Trabalho, que compete ao Sistema Único de Saúde (SUS) a execução das ações de saúde do trabalhador, conforme determina a Constituição Federal. se sobrepõe nem entra em conflito com a competência dos Estados e dos Municípios em editar, de forma suplementar, normas de proteção e defesa da saúde, em especial do trabalhador, por se situarem em campos distintos, autônomos, ainda que conexos pelo bem jurídico que se pretende proteger.

Os trabalhadores têm o direito ao trabalho em condições seguras e saudáveis não condicionado à existência de vínculo trabalhista, ao caráter e natureza do trabalho.

É nesse sentido que se insere o esforço de definição de uma política de governo, que articule as competências e normas no âmbito do Trabalho, da Previdência Social e da Saúde, às quais se juntaram, mais recentemente, as PNSST versão de 12/11/2004 11 ações do Ministério de Meio Ambiente, devendo ser ampliada para todos setores e esferas de Governo.

A OMS vem implementando de um Plano de Ação Global de Saúde dos Trabalhadores 2008-2014 aprovada pela Assembleia Mundial de Saúde em 2007, No Brasil, recentemente publicou-se duas importantes políticas: Portaria $\mathrm{N}^{\mathrm{o}} 1.823$, de 23 de agosto de 2012 - Política Nacional de Saúde do Trabalhador e da Trabalhadora, e o Decreto No 7602, de 7 de novembro de 
2011 - Política Nacional de Segurança e Saúde no Trabalho - PNSST.

No Art. $2^{\circ}$ A Política Nacional de Saúde do Trabalhador e da Trabalhadora tem como finalidade definir os princípios, as diretrizes e as estratégias a serem observados pelas três esferas de gestão do Sistema Único de Saúde (SUS), para o desenvolvimento da atenção integral à saúde do trabalhador, com ênfase na vigilância, visando a promoção e a proteção da saúde dos trabalhadores e a redução da morbimortalidade decorrente dos modelos de desenvolvimento e dos processos produtivos.

A Política Nacional de Segurança e Saúde no Trabalho - PNSST, tem por objetivos a promoção da saúde e a melhoria da qualidade de vida do trabalhador e a prevenção de acidentes e de danos à saúde advindos, relacionados ao trabalho ou que ocorram no curso dele, por meio da eliminação ou redução dos riscos nos ambientes de trabalho.

É nesse contexto, que ao analisar as condições que o trabalhador se depara no âmbito do trabalho, existe uma contradição no que preconiza a Política Nacional de Segurança e Saúde no trabalho e o que contempla nas diretrizes no Sistema Único de Saúde sob a execução das ações de saúde do trabalhador, tendo em vista, ser um dos entraves e enfraquecimento de uma Política efetiva e atuante.

É perceptível, os avanços e as contradições das políticas públicas que ocorre em detrimento das políticas sociais, da insuficiente ação do Estado no âmbito da prevenção e, por fim, dos desafios colocados aos serviços pela recémpublicada Política Nacional de Saúde do Trabalhador e da Trabalhadora.

Diante das pesquisas realizadas, é notável o entrave no que concerne aos direitos dos trabalhadores, especificamente os trabalhadores da rede sus hospitalar que é a temática abordada deste trabalho. Se deparam cotidianamente com condições desagradáveis e desumanas diante das condições que são postas no âmbito do trabalho e. Por sua vez, os trabalhadores ficam mais vulneráveis a doenças, assim, neste sistema, o trabalhador apesar de ser o personagem mais importante, uma vez que é o dono da força de trabalho que move o desenvolvimento produtivo, vivencia constantemente as precárias condições de trabalho, em razão de diversas formas de exploração a que é submetido. 


\section{REFERÊNCIAS}

ANTUNES, R. Dimensões da crise as metamorfoses do mundo do trabalho. Revista Serviço Social e Sociedade, Cortez, 2013.

DIAS, E. C. et al. Employment conditions and health inequities: a case study of Brazil. Cad. Saúde Pública, v.27, n.12, p.2452-2460, 2011.

DUBEUX, L. S.; FREESE, E.; REIS, Y. A. C. Avaliação dos serviços de urgência e emergência da rede hospitalar de referência no Nordeste brasileiro. Cad. Saúde Publica, v.26, n.8, p.1508-1518, 2010.

HÄMMIG， O.; BRAUCHLI, R.; BAUER, G. Effort-reward and work-life imbalance, general stress and burnout among employees of a large public hospital in Switzerland. Swiss Med Wkly, v.142, w13577, 2012.

HIRIGOYEN, M-F. Assédio moral: a violência perversa no cotidiano. Rio de Janeiro: Bertrand Brasil; 2011.

HIRIGOYEN, M-F. Mal-estar no trabalho: redefinindo o assédio moral. 8th ed.Rio de Janeiro: Bertrand Brasil; 2015.

Johnston A, Abraham L, Greenslade J et al. Review article: Staff perception of the emergency department workingenvironment: Integrative review of the literature. Emerg Med Australas. [Internet], v.28, n.1, p.7-26, 2016.

KONDER, M. T. et al. The current scenario of emergency care policies in Brasil. BMC Health Services Research, v.13, n.70, 2013.

MATTOS, R.A. Direito, Necessidades de Saúde e Integralidade. In: PINHEIRO, R.; MATTOS, R. A. (Org.). Construção social da demanda: direito à saúde, trabalho em equipe, participação e espaços públicos. Rio de Janeiro.: Cepesc/Uerj. Abrasco., 2005. P33-46.

MOMENI, M. et al. Evaluation of factors affecting psychological morbidity in emergency medicine practitioners. Wld $\mathrm{J}$ Emerg Med. [Internet]. 2016 [cited Jul 16, 2018]; 7:203-7.

PAI, D. D.; LAUTERT, L. O trabalho em urgência e emergência e a relação com a saúde das profissionais de enfermagem.

Latino-Am. Enfermagem, v.16, n.3, p.439-444, 2008.

PAIM, J. S. A Constituição Cidadã e os 25 anos do Sistema Único de Saúde. Cad. Saúde Pública, v.29, n.10, p.1927-1953, 2013.

SOUZA, M.E.L.; C.J.S. Trabalho, saúde e identidade: repercussões do retorno ao trabalho, após afastamento por doenças ou acidente, na identidade profissional. Saúde, Ética \& Justiça, v. 12, n. 1, p.2232, 2007. 